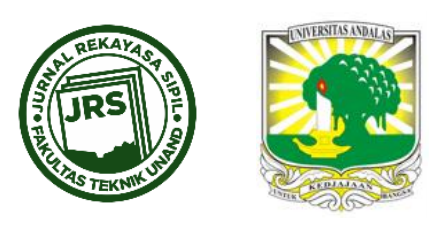

JURNAL REKAYASA SIPIL (JRS-UNAND)

Vol. 13 No. 1, Februari 2017 Diterbitkan oleh:

Jurusan Teknik Sipil, Fakultas Teknik, Universitas Andalas (Unand)

ISSN (Print) : 1858-2133

ISSN (Online) : 2477-3484

http://jrs.ft.unand.ac.id

\title{
STUDI PERBANDINGAN PRIORITAS PENANGANAN JALAN PROVINSI DI SUMATERA BARAT
}

\author{
TONI ANTONIUS ${ }^{1}$, PURNAWAN $^{2}$, YOSRITZAL $^{3}$ \\ ${ }^{1}$ Prodi Magister Teknik Sipil, Fakultas Teknik,Universitas Andalas (a2onius_toni@yahoo.com) \\ ${ }^{2} J u r u s a n$ Teknik Sipil, Fakultas Teknik, Universitas Andalas (ه purnawan@ft.unand.ac.id) \\ 3Jurusan Teknik Sipil, Fakultas Teknik, Universitas Andalas (yosritzal@ft.unand.ac.id)
}

Naskah diterima : 24 Desember 2016. Disetujui: 12 Januari 2017. Diterbitkan : 4 Maret 2017

\begin{abstract}
ABSTRAK
Visi Dinas Prasarana Jalan Tata Ruang dan Permukiman Provinsi Sumatera Barat adalah mewujudkan prasarana jalan handal guna memacu daya saing ekonomi kerakyatan dan ekonomi skala besar. Tujuannya untuk pemerataan pembangunan di segala bidang. Dibutuhkan jalan yang stabil dan selalu mendapat penanganan. Keterbatasan dana diperlukan skala prioritas.. Tujuan penelitian menentukan urutan proritas penanganan jalan dengan metoda AHP, AMK, Metoda Bina Marga dan dilaksanakan Dinas serta membandingkan hasil urutan prioritas dengan metoda. Metoda AHP menggunakan pembobotan (weighting) hasil persepsi responden dan penilaian (scoring) dengan liniear models menghasilkan prioritas utama dalam pemeliharaan rutin adalah ruas Air Balam - Air Bangis (034), pemeliharaan berkala ruas Baso - Batusangkar (036), penanganan peningkatan Payakumbuh - Suliki - Koto Tinggi (069.2) dan pembangunan adalah ruas Pasar Baru - Alahan Panjang (073). Metoda AMK menggunakan pembobotan dan penilaian dari responden menghasilkan penanganan rutin pada ruas Air Balam - Air Bangis (034), penanganan berkala pada ruas Simpang Koto Baru - Tj. Simalidu (011), penanganan peningkatan pada ruas Pangkalan - Sialang - Gelugur (076) dan penanganan pembangunan pada ruas Abai Sangir - Sungai Dareh (056.3). Metoda Bina Marga menggunakan volume Lalu Lintas Harian (LHR) sebagai input utama menghasilkan penanganan rutin pada ruas Surian - Simpang Pd. Aro (014.2), berkala pada ruas Jl. Veteran (Payakumbuh) (069.1), peningkatan pada ruas Simpang Duku Pariaman (075) dan pprioritas utama dalam penanganan pembangunan adalah ruas Pasar Baru - Alahan Panjang (073). Yang dilaksanakn Dinas penanganan pembangunan pada ruas jalan Alahan Panjang - Pasar Baru (073), ruas jalan Alahan Panjang - Kiliran Jao (082) dan ruas jalan Guguak Cino - Sawahlunto (038) dan penanganan peningkatan diprioritaskan pada ruas jalan Payakumbuh-Suliki-Koto-Tinggi (069.2).
\end{abstract}

Kata kunci : prioritas, perbandingan, AHP, AMK, bina marga

\section{PENDAHULUAN}


Salah satu visi dari Dinas Prasarana Jalan Tata Ruang dan Permukiman Provinsi Sumatera Barat adalah mewujudkan prasarana jalan yang handal guna memacu daya saing ekonomi kerakyatan dan ekonomi skala besar. Tujuannya untuk pemerataan pembangunan di segala bidang. Faktor-faktor pendukung seperti tersedianya jalan yang stabil dan selalu mendapat penanganan sangat dibutuhkan. Keterbatasan anggaran menjadi penyebab tidak meratanya penanganan.

Tujuan penelitian menentukan urutan prioritas penanganan jalan menggunakan Metoda Analytic Hirarchie Process (AHP), Analisis Multi Kriteria (AMK), Metoda Bina Marga, dan membandingkan penanganan yang dilaksanakan Dinas Prasarana Jalan Tata Ruang dan Permukiman Provinsi Sumatera Barat. Manfaat dari penelitian ini adalah mengetahui bahwa ada metoda dalam penentuan prioritas penanganan jalan.

\section{METODOLOGI PENELITIAN}

Data primer penelitian melalui penyebaran kuesioner. Data sekunder yang digunakan hasil survey kondisi jalan dan data penanganan fisik Bidang Pelaksana Jalan dan Jembatan tahun 2012 - 2014. Penentuan ruas jalan sesuai Surat Keputusan Gubernur Sumatera Barat Nomor 600-920-2-12 tanggal 28 Desember 2012 dengan menggunakan Metoda AHP. AMK, Metoda Bina Marga. Hasil dari metoda-metoda tersebut dibandingkan dengan realisasi di dinas dalam 3 tahun terakhir.

\subsection{Analytical Hierarrchi Process (AHP)}

Gambar hirarki penentuan prioritas dapat dilihat Gambar 1.

Persoalan keputusan Analytic Hierarchy Process (AHP) dapat dikonstruksikan sebagai diagram bertingkat, yang dimulai dengan tujuan, lalu kriteria, dan sub kriteria.

Pemberian nilai preferensi berpasangan dengan nilai dalam skala 1 sampai dengan 9 dari skala Saaty (1986). Setelah semua matriks terbentuk dan semua perbandingan tiap pasangan elemen didapat, selanjutnya dapat dihitung matriks eigen (eigen vector), untuk masing-masing kriteria dengan menggunakan persamaan (1)

$$
\mathrm{Wi}={ }^{\mathrm{n}} \sqrt{ } a_{i 1} a_{i 2} a_{13} \ldots . a_{1 n}
$$

Matriks yang diperoleh tersebut merupakan eigen vector yang juga merupakan bobot kriteria. Bobot kriteria atau eigen vector adalah $\lambda i$, yang dihitung dengan persamaan (2).

$$
\Lambda_{i}=W_{i} \sum W_{i}
$$

dengan nilai eigen vector maksimum (terbesar) atau $\lambda$ maks diperoleh dari persamaan (2) ke dalam persamaan (3).

$\Lambda$ maks $=\sum\left(a_{i j} X_{j}\right)$

Penyimpangan dari konsistensi dinyatakan dengan

$$
C_{\mathrm{I}}=(\lambda \text { maks }-n / n-1
$$

dimana :

CI = Indeks konsistensi;

44 | JURNAL REKAYASA SIPIL 
$\lambda$ maks $=$ Nilai eigen maksimum; dan

$\mathrm{n} \quad=$ Ukuran matriks

yaitu matriks random dengan skala penilaian $1-9$ beserta kebalikannya sebagai RI (indeks random).

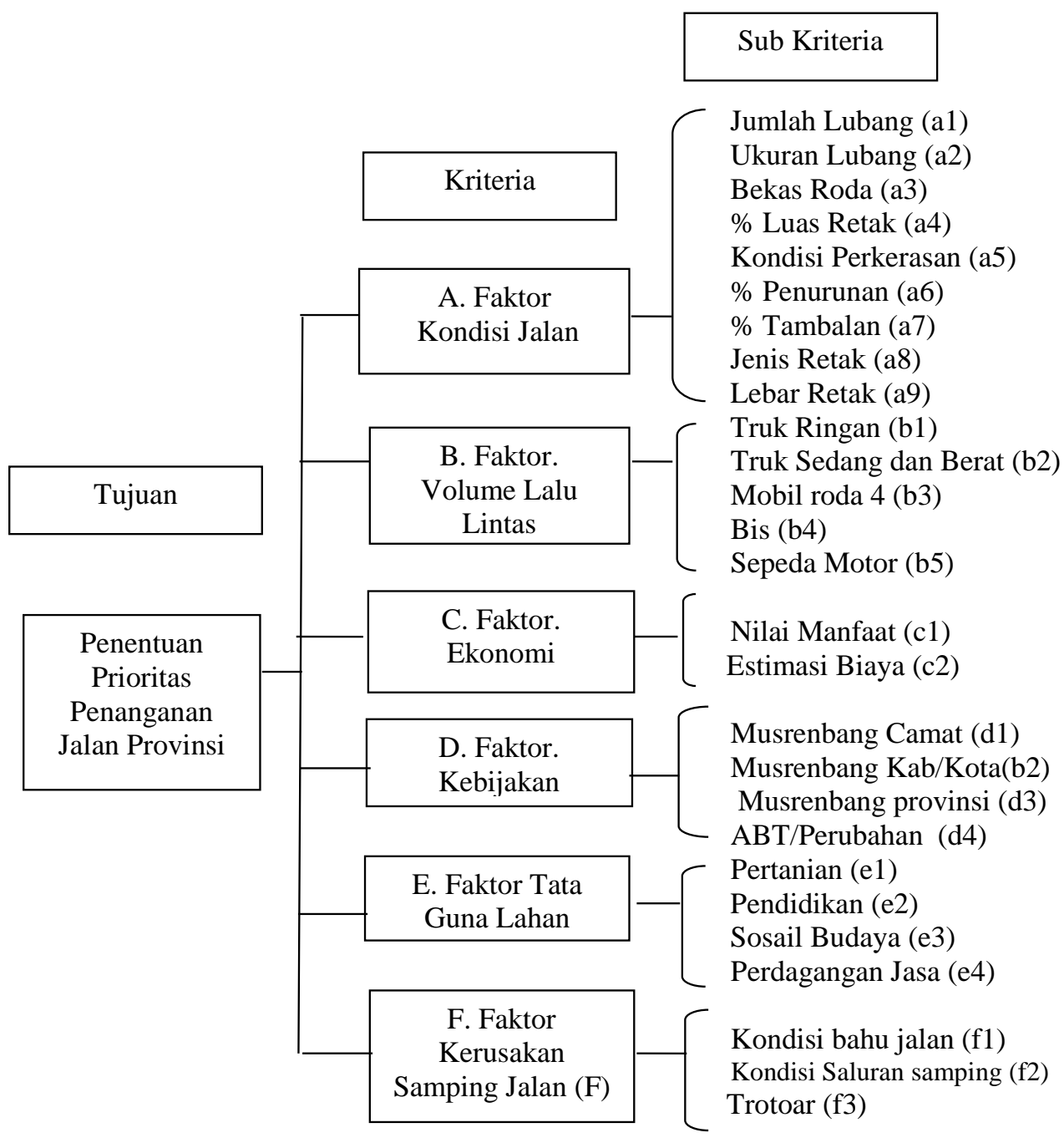

\section{Gambar 1. Level Hirarki Penentuan Prioritas}

Liniers models adalah untuk menentukan penilaian (Scoring) prioritas dari penjumlahan hasil pengalian antara bobot dan nilai.

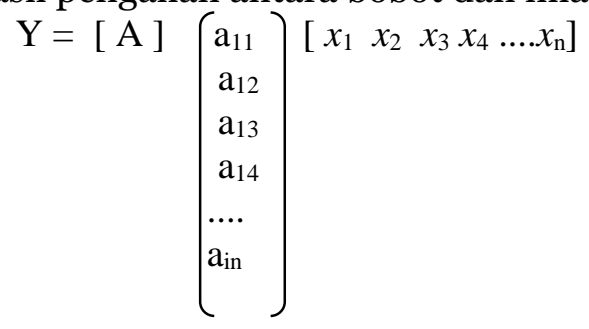




$$
\left(\mathrm{a}_{11} X_{1}\right)+\left(\mathrm{a}_{12} X_{2}\right)+\left(\mathrm{a}_{13} X_{3}\right)+\left(\mathrm{a}_{14} \mathrm{x} X_{4}\right) \ldots .\left(\mathrm{a}_{\mathrm{i} 9} \mathrm{x}_{9}\right)=\mathrm{h}_{i}
$$

Nilai Prioritas : $\mathrm{Y}=[\mathrm{A}]\left[\mathrm{h}_{\mathrm{i}}\right]+[\mathrm{B}]\left[\mathrm{h}_{\mathrm{j}}\right]+[\mathrm{C}]\left[\mathrm{h}_{\mathrm{k}}\right]+[\mathrm{D}]\left[\mathrm{h}_{\mathrm{l}}\right]+[\mathrm{E}]\left[\mathrm{h}_{\mathrm{m}}\right]+[\mathrm{F}]\left[\mathrm{h}_{\mathrm{n}}\right]$

\subsection{Analisis Multi Kriteria (AMK)}

Dimulai dari proses pengambilan keputusan dengan membuat matriks perbandingan berpasangan untuk setiap responden guna mendapatkan bobot kriteria. Penilaian kinerja kriteria dengan memberikan nilai antara $0 \mathrm{~s} / \mathrm{d} 10$ terhadap ruas jalan yang diberikan responden.

Proses penilaian (scoring) variabel kriteria terukur secara kuantitatif dilakukan sebagai berikut :

1. Usulan dengan angka variabel yang terbaik dari suatu kriteria diberi skor maksimum, yakni 10.

2. Skor untuk alternatif lain (yang lebih rendah) dihitung sebagai proporsi terhadap variabel pada alternatif dengan variabel terbaik menggunakan formulasi berikut :

Untuk variabel terbaik adalah angka tertinggi:

Skor kriteria $\mathrm{X}=($ Nilai variabel $\mathrm{X}) /($ Nilai variabel terbaik)*10

Untuk variabel terbaik adalah angka terendah:

Skor kriteria $\mathrm{X}=($ Nilai variabel terbaik $) /($ Nilai variabel $\mathrm{X}) * 10$

Tabel 1. Matrik Kinerja Alternatif

\begin{tabular}{|c|c|c|c|c|c|}
\hline & Kriteria & Kriteria & \multirow[b]{2}{*}{ ….... } & Kriteria & \multirow{2}{*}{ Kinerja } \\
\hline & I & II & & $\mathrm{J}$ & \\
\hline Alternatif 1 & $\mathrm{~S} 11 * \mathrm{~W} 1$ & $\mathrm{~S} 12$ * W2 & $\ldots \ldots$. & $\mathrm{S} 1 \mathrm{j} * \mathrm{Wj}$ & P1 \\
\hline Alternatif 2 & $\mathrm{~S} 21^{*} \mathrm{~W} 2$ & $\mathrm{~S} 22 * \mathrm{~W} 2$ & ........ & $S 2 j * W j$ & $\mathrm{P} 2$ \\
\hline Alternatif i & $\mathrm{Si}^{*}{ }^{*} \mathrm{~W} 1$ & $\mathrm{Si}_{2} * \mathrm{~W} 2$ & ….... & $\mathrm{Sij}^{*} \mathrm{Wj}$ & Pi \\
\hline
\end{tabular}

\subsection{Analisis Metoda Bina Marga}

menentukan nilai manfaat lalu lintas dan menentukan nilai biaya konstruksi jalan (menggunakan tabel manfaat lalu lintas dan tabel spesifikasi pekerjaan). Diperbandingkan secara langsung untuk memperoleh NPV (Net present Value). (Ditjen Bina Marga, 1990)

\subsection{Analisa Dinas Prasarana Jalan Tata Ruang dan Permukiman Provinsi Sumatera Barat}

Penanganan pada ruas-ruas jalan provinsi selama periode 2012 - 2014 akan didapatkan suatu matriks penanganan. Didapat pola penanganan yang selama ini dipakai Dinas Prasrana Jalan Tata Ruang dan Permukiman provinsi Sumatera Barat.

\section{HASIL DAN PEMBAHASAN}


Tabel 2. Perbandingan Hasil Analisa dengan Dinas

\begin{tabular}{|c|c|c|c|c|}
\hline & Metoda AHP & Metoda AMK & Metoda BM & Penanganan Dinas \\
\hline Input & $\begin{array}{l}\text { Data primer persepsi } \\
\text { responden } \\
\text { Kondisi jalan } \\
\text { ditentukan dari input } \\
\text { penilaian setiap sub } \\
\text { kriteria kondisi jalan. }\end{array}$ & 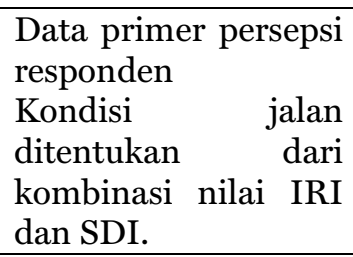 & $\begin{array}{l}\text { Data teknis berupa } \\
\text { LHR } \\
\text { Kondisi jalan } \\
\text { ditentukan dari } \\
\text { kombinasi nilai IRI } \\
\text { dan SDI }\end{array}$ & $\begin{array}{l}\text { Data IIRMS } \\
\text { Kondisi Jalan diambil } \\
\text { dari nilai IRI } \\
\text { Jenis penanganan } \\
\text { pembangunan, } \\
\text { peningkatan dan rutin }\end{array}$ \\
\hline Proses & $\begin{array}{lr}\begin{array}{l}\text { Melalui } \\
\text { Pembobotan }\end{array} & \text { proses } \\
\text { (responden) } & \text { dan } \\
\text { Penilaian } & \text { Linier } \\
\text { Models. } & \\
\begin{array}{l}\text { Penilaian } \\
\text { dengan linier }\end{array} & \text { (Scoring) } \\
\end{array}$ & $\begin{array}{l}\text { Melalui Pembobotan } \\
\text { dan Penilaian } \\
\text { Pembobotan dengan } \\
\text { matriks } \\
\text { perbandingan } \\
\text { berpasangan dan } \\
\text { (Scoring) dengan } \\
\text { Penilaian Kinerja } \\
\text { Alternatif. }\end{array}$ & $\begin{array}{lr}\text { Penentuan } & \text { nilai } \\
\text { manfaat dari } & \text { tabel } \\
\text { Nilai Manfaat Lalu } \\
\text { Lintas } & \\
\text { Prioritas } & \text { selisih } \\
\text { nilai } & \text { Manfaat } \\
\text { dengan } & \text { Perkiraan } \\
\text { Biaya } & \end{array}$ & $\begin{array}{l}\text { Pengaruh } \\
\text { kebijakan/politis } \\
\text { Melalui pembahasan- } \\
\text { pembahasan. }\end{array}$ \\
\hline $\begin{array}{l}\text { Outpu } \\
\mathrm{t}\end{array}$ & $\begin{array}{l}\text { Menghasilkan bobot } \\
\text { kriteria dan sub } \\
\text { kriteria hasil persepsi } \\
\text { responden } \\
\text { Penanganan rutin, } \\
\text { berkala peningkatan } \\
\text { dan pembangunan. }\end{array}$ & $\begin{array}{l}\text { Menghasilkan bobot } \\
\text { kriteria hasil persepsi } \\
\text { responden } \\
\text { Penanganan rutin } \\
\text { berkala, peningkatan, } \\
\text { pembangunan. }\end{array}$ & $\begin{array}{l}\text { Faktor volume lalu } \\
\text { lintas } \\
\text { mempengaruhi } \\
\text { dalam prioritas. } \\
\text { Penanganan rutin, } \\
\text { berkala, } \\
\text { peningkatan, dan } \\
\text { pembangunan. }\end{array}$ & $\begin{array}{l}\text { Menghasilkan jenis } \\
\text { penanganan } \\
\text { peningkatan, } \\
\text { pembangunan }\end{array}$ \\
\hline
\end{tabular}




\subsection{Hasil Prioritas Metoda AHP}

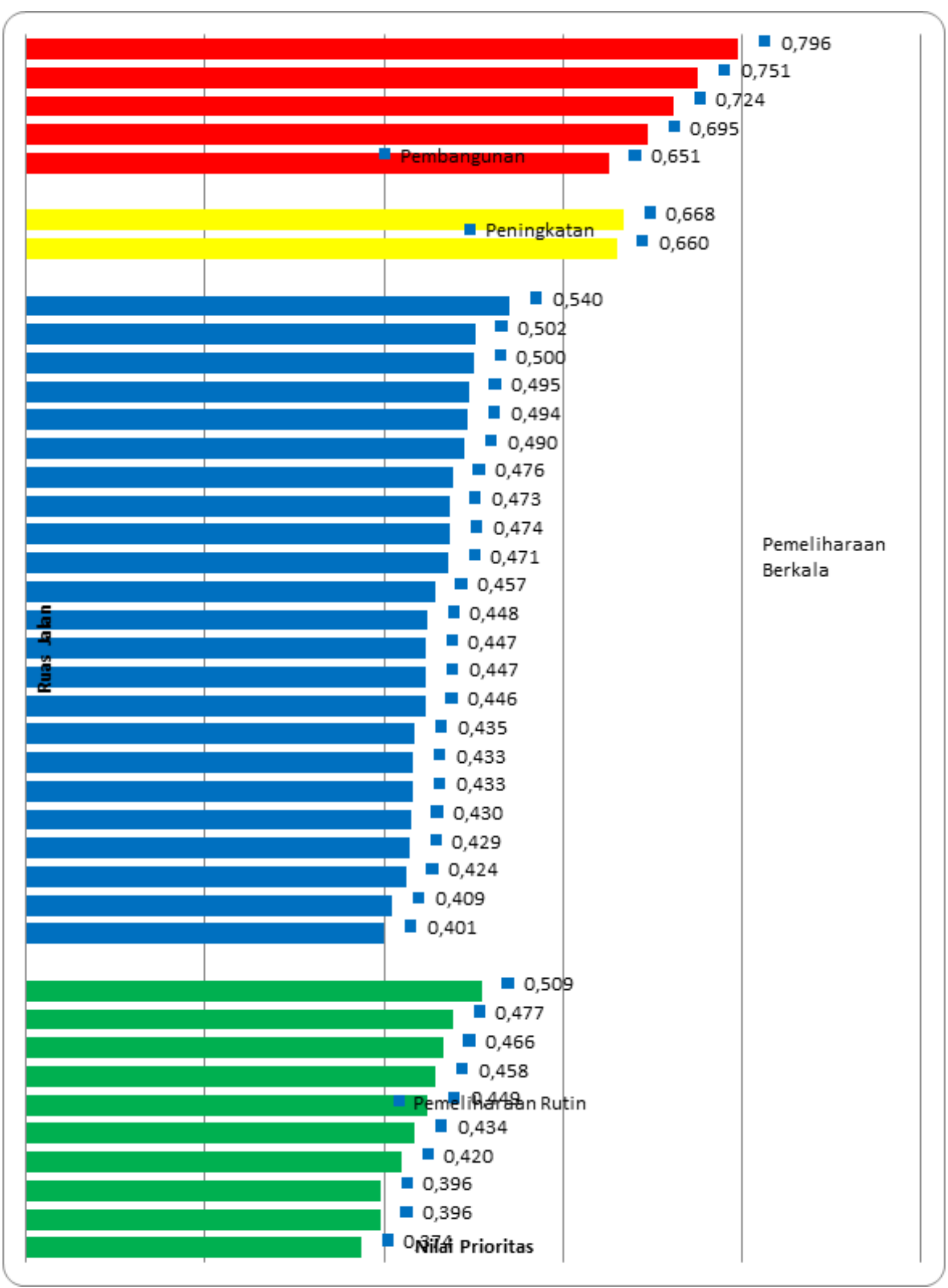

Gambar 2. Hasil Prioritas Metoda AHP 


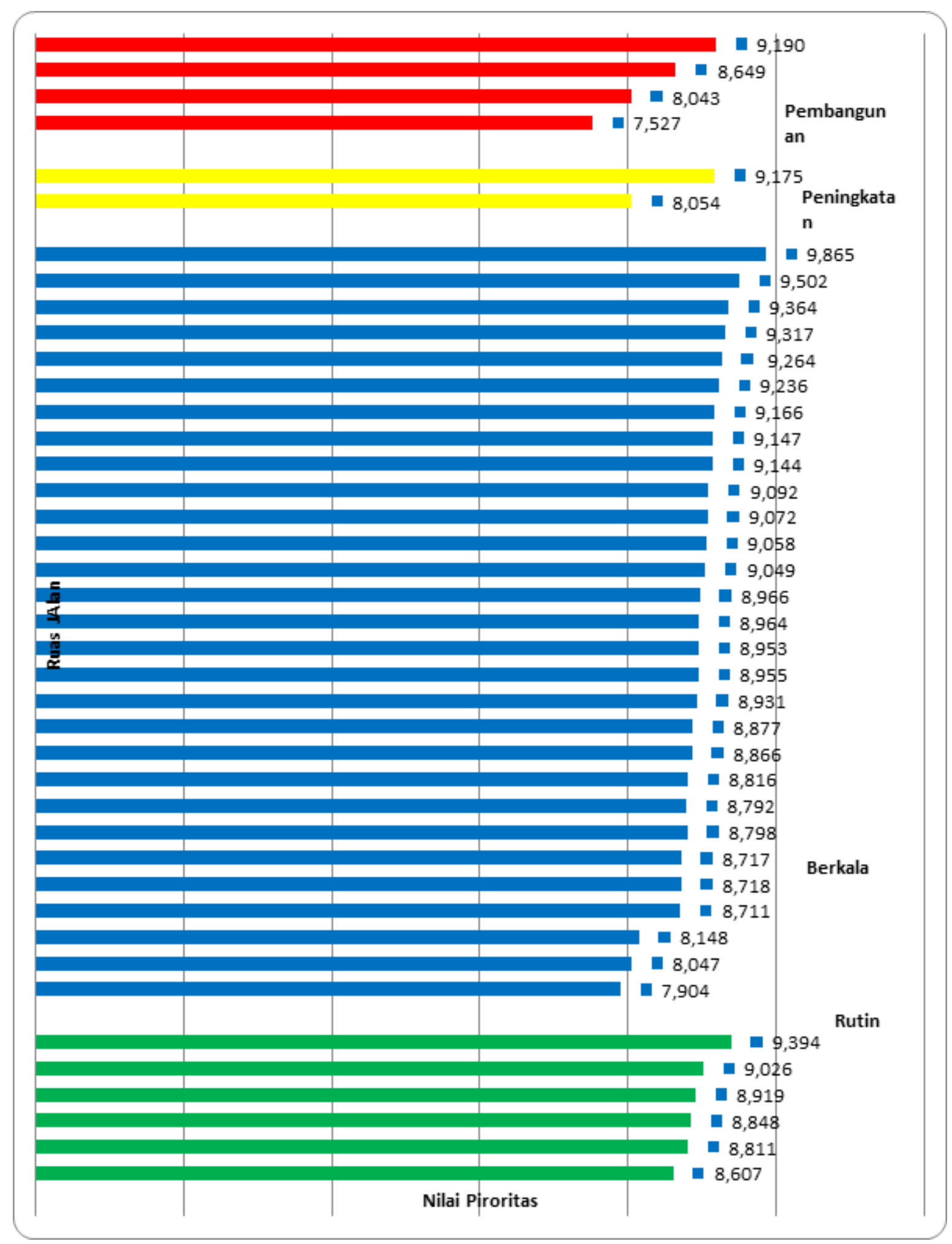

Gambar 3. Hasil Prioritas Metoda AMK 


\subsection{Hasil Prioritas Metoda Bina Marga}

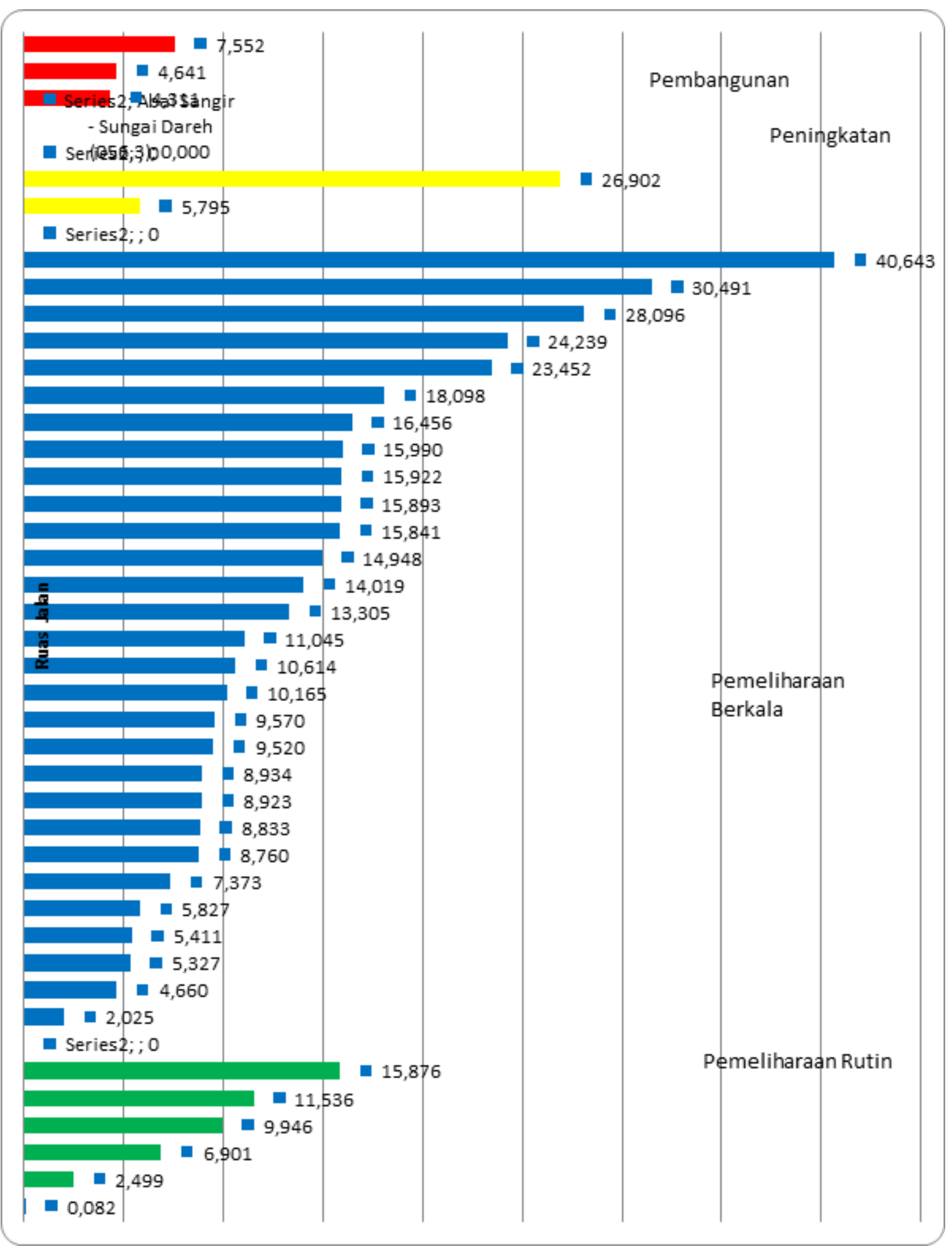

Gambar 4. Hasil Prioritas Metoda Bina Marga 


\subsection{Pelaksanaan Dinas Prasarana Jalan Tata Ruang dan Permukiman}

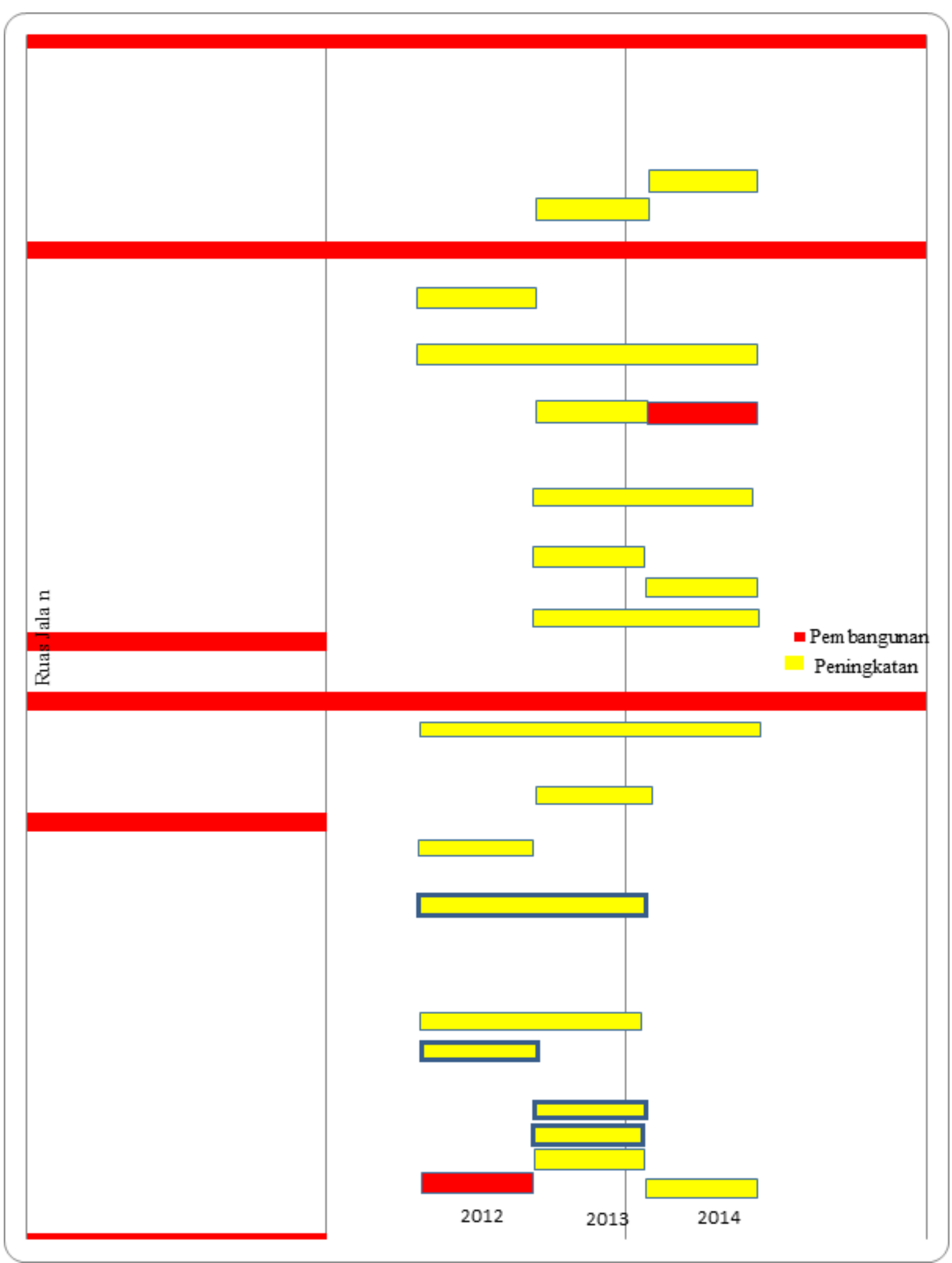

Gambar 5. Hasil Prioritas Dinas Prasjal Tarkim dalam Tahun Penanganan 2012-2014 


\subsection{Perbandingan Prioritas Penanganan Jalan}

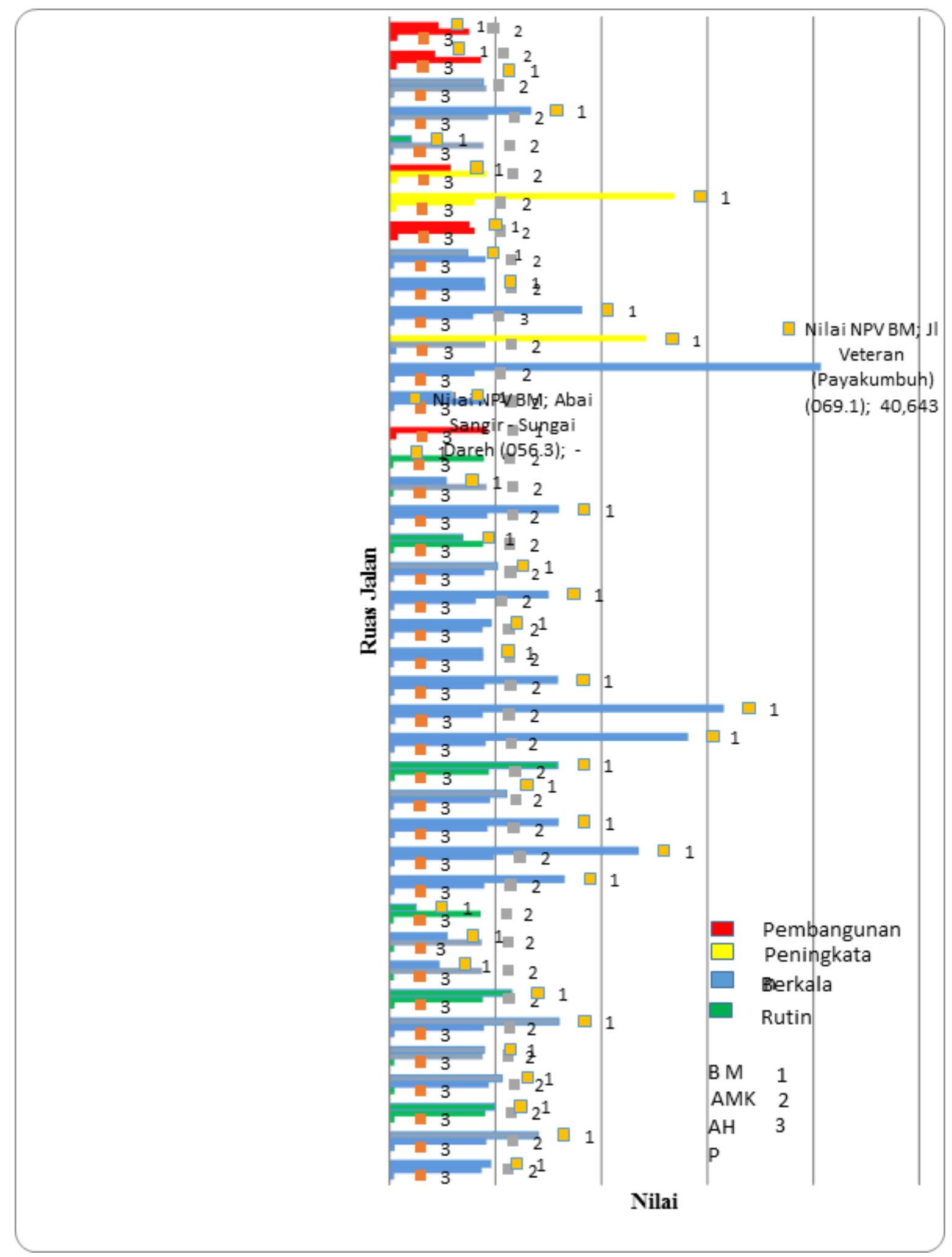

Gambar 6. Perbandingan Nilai Metoda Prioritas 


\section{KESIMPULAN}

1. Ruas Jalan yang menjadi prioritas pada masing - masing metoda dan yang dilakukan Dinas adalah sebagai berikut :

a. Hasil Metoda AHP:

\begin{tabular}{|l|l|l|l|}
\hline Rangking & Ruas Jalan & Nilai & Jenis Penanganan \\
\hline 1 & Alahan Panjang - Pasar Baru (073) & 0,796 & Pembangunan \\
2 & Alahan Panjang - Kiliran Jao (082) & 0,751 & Pembangunan \\
5 & Simp. Duku - Pariaman (075) & 0,668 & Peningkatan \\
6 & Payakumbuh-Suliki-KotoTinggi (069.2) & 0,660 & Peningkatan \\
8 & Baso - Batusangkar (036) & 0,540 & Berkala \\
9 & Air Balam - Air Bangis (034.2) & 0,509 & Rutin \\
\hline
\end{tabular}

b. Hasil Metode Analisis Multi Kriteria:

\begin{tabular}{|l|l|l|l|}
\hline Rangking & Ruas Jalan & Nilai & Jenis Penanganan \\
\hline 1 & Sicincin - Kurai Taji (028) & 9,86 & Berkala \\
2 & Simpang Empat - Sasak (033) & 9,50 & Berkala \\
3 & Air Balam - Air Bangis (034) & 9,39 & Rutin \\
4 & Simp. Koto Baru - Tj. Simalidu (011) & 9,36 & Berkala \\
8 & Abai Sangir - Sei. Dareh (056.3) & 9,19 & Pembangunan \\
9 & Pangkalan Sialang Gelugur (076) & 9,18 & Peningkatan \\
\hline
\end{tabular}

c. Hasil Metode Bina Marga :

\begin{tabular}{|l|l|l|l|}
\hline Rangking & Nama Ruas Jalan & $\begin{array}{l}\text { Nilai } \\
\text { NPV } \\
(\text { juta/km) }\end{array}$ & Jenis Penanganan \\
\hline 1 & Jl. Veteran (Payakumbuh)(069 1) & 4.064 & Berkala \\
2 & Baso - Batusangkar (036) & 3.149 & Berkala \\
4 & Simpang Duku - Pariaman (028) & 2.690 & Peningkatan \\
6 & Sicincin-Kurai Taji (028) & 2.345 & Berkala \\
17 & Surian - Simp Pd. Aro (014.2) & 1.154 & Rutin \\
28 & Pasar Baru - Alahan Panjang (073) & 755 & Pembangunan \\
\hline
\end{tabular}

d. Prioritas yang dilaksanakan Dinas selama 3 tahun terakhir adalah:

\begin{tabular}{|l|l|l|l|}
\hline $\begin{array}{l}\text { Pemeliharaan } \\
\text { Rutin }\end{array}$ & $\begin{array}{l}\text { Pemeliharaan } \\
\text { Berkala }\end{array}$ & Peningkatan & Pembangunan \\
\hline $\begin{array}{l}\text { Setiap tahun } \\
\text { pada semua } \\
\text { ruas jalan } \\
\text { Provinsi }\end{array}$ & Tidak & $\begin{array}{l}\text { Payakumbuh - Suliki - } \\
\text { Koto Tinggi (069.2) } \\
\text { Baso - Bataksanakan } \\
\text { (038) }\end{array}$ & $\begin{array}{l}\text { Alahan Panjang- Kiliran } \\
\text { Jao (082) } \\
\text { Guguak Cino Swahlunto } \\
\text { (038) } \\
\text { Pasar Baru- Alahan } \\
\text { Panjang (072) }\end{array}$ \\
\hline
\end{tabular}

2. Kombinasi kelebihan-kelebihan yang ada dari metoda tersebut baik dari input, proses ataupun output bisa mengatasi permasalahan dalam prioritas penanganan jalan.

3. Metoda yang disarankan, untuk pemeliharaan rutin menggunakan metoda Dinas Prasjal Tarkim Sumbar dan jenis penanganan lainnya dilaksanakan dengan AHP dengan alasan perpaduan antara persepsi responden (pembobotan) dengan penggunaan linier models (penilaian) menunjukkan konsistensi. 


\section{DAFTAR PUSTAKA}

Ditjen Bina Marga, (1990), Petunjuk Teknis Perencanaan dan Penyusunan Program Jalan provinsi. Surat Keputusan No.77/KPTS/Db/1990. Jakarta: Departemen Pekerjaan Umum RI.

Saaty, T.L., (1986), Proses Hirarki Analitik untuk Pengambilan Keputusan Dalam Situasi yang Kompleks, Jakarta : PT Pustaka Binman Pressindo. 